\title{
SOCIALIZAÇÃO POLÍTICA E INTERNET NA CONSTRUÇÃO DE UMA CULTURA POLÍTICA JUVENIL NO SUL DO BRASIL*
}

\author{
Marcello Baquero ${ }^{1}$ \\ Rute Vivian Angelo Baquero ${ }^{2}$ \\ Jennifer Azambuja de Morais ${ }^{3}$
}

\begin{abstract}
RESUMO: Expectativas e demandas por uma sociedade mais igualitária e inclusiva vêm sendo disseminadas pela internet por meio de redes sociais. A importância da internet no Brasil se deve ao fato de que novos espaços têm sido criados para a formação de identidades coletivas e de uma nova forma de comunicar as demandas da juventude perante o Estado, constituindose, portanto, em uma nova modalidade de socializaçáo política. O perfil dos jovens que participaram dos protestos nos últimos cinco anos aponta para uma nova geração de "rebeldes" que desejam expurgar as instituiçóes existentes. Esses acontecimentos trazem à tona a discussão da relação entre o desenvolvimento político do sujeito e a construçáo de uma cultura política democrática via socialização política.
\end{abstract}

Palavras-chave: Democracia. Cultura política. Internet. Socialização política. Brasil.

\section{POLITICAL SOCIALIZATION AND INTERNET IN THE CONSTRUCTION OF A YOUTH'S POLITICAL CULTURE IN SOUTHERN BRAZIL}

ABSTRACT: Expectations and demands for a more equitable and inclusive society have been disseminated over the internet through social networks. The importance of the internet in Brazil is because new spaces appeared for the formation of collective identities and a new way to communicate with the State demanded by the youth, constituting therefore a new form of political socialization. The profile of young people who took part in protests

\footnotetext{
${ }^{*} \mathrm{O}$ artigo se baseia em dados coletados pela pesquisa Democracia, mídia e capital social: um estudo comparativo da socialização de jovens do Sul do Brasil, realizado nas três capitais da regiáo Sul, entre 2015 e 2016, com alunos, de 13 a 24 anos, do ensino médio de escolas públicas e privadas escolas. A pesquisa foi realizada pelo Núcleo de Pesquisa sobre América Latina (Nupesal), com coordenação do professor Marcello Baquero, com apoio do CNPQ.

${ }^{1}$ Universidade Federal do Rio Grande do Sul (UFRGS), Programa de Pós-Graduação em Ciência Política Porto Alegre (RS), Brasil. E-mail: nupesal@yahoo.com.br

${ }^{2}$ UFRGS, Núcleo de Pesquisa sobre a América Latina (NUPESAL) - Porto Alegre (RS), Brasil.

E-mail: rutevivian@gmail.com

${ }^{3}$ UFRGS, Programa de Pós-Graduação em Ciência Política, NUPESAL - Porto Alegre (RS), Brasil.

E-mail: jennifer.amorais@gmail.com

DOI: 10.1590/ES0101-73302016166022
} 
in the past five years points to a new generation of "rebels" who wish to expulse existing institutions. These events bring up the discussion of the relationship between the youth's political development and the construction of a democratic political culture through political socialization.

Keywords: Democracy. Political culture. Internet. Political socialization. Brazil.

\section{LA SOCIALISATION POLITIQUE ET L'INTERNET DANS LA CONSTRUCTION D'UNE CULTURE POLITIQUE DE LA JEUNESSE DANS LE SUD DU BRÉSIL}

RESUMÉ: Les attentes et les exigences d'une société plus équitable et inclusive a commencé à être diffusée sur internet via réseaux sociaux. L'importance de l'internet au Brésil est due au fait que de nouveaux espaces ont été créés pour la formation des identités collectives et une nouvelle façon de communiquer les demandes des jeunes auprès de l'État, ce qui constitue donc une nouvelle forme de socialisation politique. Le profil des jeunes qui ont pris part à des manifestations au cours des cinq dernières années, indique une nouvelle génération de "rebelles » qui veulent expurger les institutions existantes. Ces événements rassemblent la discussion de la relation entre le développement politique du sujet et la construction d'une culture politique démocratique à travers la socialisation politique.

Mots-clés: Démocratie. Culture politique. Internet. Socialisation politique. Brésil.

\section{Introdução}

U

ma das principais características da consolidação de uma cultura política participativa - o apoio político ao regime democrático — constitui-se na etapa mais difícil do processo de consolidação democrática, uma vez que exige a legitimidade da ordem política. Vários autores — Diamond, 1994; Weffort, 1998; Merkel, 1999 - consideram a legitimidade como o eixo central para avaliar o grau de consolidação democrática de um país. Quanto maior o nível de legitimidade mais fortalecida está a ordem política e quanto mais a ordem política se consolida maior a probabilidade de sua persistência. Esse processo se materializa quando, em situaçóes de crises políticas e econômicas graves, a maioria da população acredita que qualquer mudança política deve surgir com base nos parâmetros de ordem democrática.

Da perspectiva da cultura política, o apoio à política e ao sistema político se dá com base em experiências positivas contínuas; portanto, experiências contínuas de caráter negativo com o desempenho das instituiçóes políticas e as ações dos gestores públicos podem desembocar no declínio de apoio e obediência a normas 
democráticas. Nesse contexto, a legitimidade da democracia pode entrar em um estado de inércia política, a qual contribui para a manutenção de práticas políticas deletérias na construção de uma cultura política participativa (BAQUERO, 2016).

Argumentamos que uma das razóes para a inércia política radica na deficiência das instituiçóes políticas, que carecem de credibilidade para estimular a participação dos cidadãos, particularmente os jovens, via canais institucionalizados. Não há, no entanto, pesquisas que focalizem o impacto da inércia na cultura política juvenil; se pressupóe que, em virtude da disponibilidade de modernas tecnologias de comunicação, a estruturação de uma cultura política juvenil participativa é uma consequência natural.

Postulamos, porém, que a despeito da emergência de novas tecnologias de informação e comunicação, o desempenho das instituiçóes políticas é essencial para o desenvolvimento de uma cultura política juvenil participativa. Nesse sentido, é imperativo examinar as intersecçôes entre cultura política, socialização política e mídia digital — internet e suas redes sociais —, no que tange à juventude.

Várias décadas após o surgimento da internet, duas coisas são inquestionáveis:

1. em termos de impacto, a internet tem excedido todas as expectativas imaginadas pelo ser humano;

2. vivemos em sociedades cada vez mais desiguais, antagônicas e, em alguns casos, intolerantes, apesar dos avanços tecnológicos.

Nesse cenário é pertinente questionar: que tipo de jovem cidadão a internet está produzindo? Qual tem sido sua influência nas culturas políticas juvenis? Qual a relaçấo entre a utilização da internet pelos jovens e a democracia? É a internet uma nova agência de socialização política?

Esses questionamentos têm gerado diferentes tipos de análise acerca das possibilidades democráticas da internet. Alguns estudos têm orientado sua preocupação em relação a como as interações digitais se constituem em indicadores de grau de participação e engajamento político (EISENBERG, 1999; MAIA, 2008; EGLER, 2010; ARAÚJO; PENTEADO; SANTOS, 2014). Um segundo conjunto de pesquisas tem problematizado a relação entre a internet e a socializaçáo política (OWEN, 2008). Um terceiro grupo tem focalizado a relação entre a internet e a formação de identidades coletivas (LAMB; POSTER, 2003; MAIA; CASTRO, 2006; SOON; KLUVER, 2014).

Tais análises se dão com base na premissa de que as geraçóes de crianças e adolescentes nas sociedades contemporâneas nascem em um ambiente de meios de informação e de comunicação sofisticados e, portanto, não enfrentam dificuldades em lidar com as ferramentas tecnológicas. São os chamados "nativos 
digitais" (digital natives), jovens que se comunicam e vivem suas relaçōes sociais de uma forma diferente de geraçóes anteriores. Subjacente a isso, se pressupóe que esse tipo de envolvimento digital está contribuindo para a construção de um novo senso de cidadania e uma cultura política juvenil mais participativa.

No entanto, embora a internet possa afetar os canais dos agentes de socialização ou agir como um novo agente social, estudos que tenham pesquisado a influência da internet como agente de socialização são escassos (BARBER, 2013), estando, ainda, em um estágio inicial e carecendo de análises empíricas.

Com base nessas consideraçóes, o objetivo deste artigo foi examinar se a internet e suas redes sociais configuram outra cultura política juvenil, diferenciada da cultura política de geraçóes juvenis anteriores — socializadas por agentes tradicionais de socialização política.

Para responder ao problema de pesquisa formulado, foi realizada uma pesquisa tipo survey, com amostras probabilísticas, em Porto Alegre, Rio Grande do Sul (em maio de 2015, com 690 casos) e em Curitiba, Paraná (em junho de 2016, com 775 casos). Aplicou-se um questionário com 69 perguntas - abertas e fechadas, sendo estas a maioria - , tendo como sujeitos da pesquisa jovens estudantes de escolas públicas e privadas, na faixa etária entre 13 e 24 anos.

$\mathrm{O}$ texto está estruturado em três partes. Na primeira, discute-se a internet como novo agente de socialização política dos jovens.Na segunda, problematiza-se fatores de contexto que, na nossa avaliação, se constituem em constrangimentos para a constituição de uma cultura política juvenil participativa - no entanto, distinta da cultura de jovens de geraçôes anteriores. $\mathrm{Na}$ terceira, analisa-se dados da pesquisa "Democracia, mídias e capital social: um estudo comparativo de socialização política dos jovens no Sul do Brasil", desenvolvida pelo Núcleo de Pesquisas sobre América Latina (NUPESAL), examinando o papel da internet e de suas redes sociais em comparação ao dos agentes tradicionais de socialização política.

\section{Socialização política e internet}

Um conjunto de iniciativas globalmente patrocinadas pelos jovens parece ter marcado uma nova forma de participação via redes virtuais no início da segunda década de nosso século: a "Primavera Árabe", no Oriente Médio; os "Indignados", em Madri; o Ocupe Wall Street, em Manhattan; e, no Brasil, as manifestações ocorridas a partir de 2013. Essas manifestações indicaram que não podemos mais ignorar a influência das novas mídias tecnológicas na formação de identidades coletivas entre os jovens.

Nesse sentido, o processo de socialização estaria, atualmente, ocorrendo em circunstâncias diferentes, nas quais a internet aparece como mecanismo central 
de outro tipo de socialização política. Ao aumentar a comunicação, além de unir grupos e indivíduos diferentes que nunca haviam tido contato anteriormente, a internet possibilita aos jovens assumirem comportamentos e causas de natureza social e política de seu interesse, constituindo-se - no que refere Feenberg (1999) —, como uma tentativa de conduzir a tecnologia para fins mais democráticos.

Musiał e Kazienko (2011) argumentam que o uso de redes sociais via internet se constitui como uma parte da subcultura da jovem geraçáo contemporânea. Esse canal tem sido utilizado pela juventude que, descrente das organizaçôes tradicionais de mediação política, passou a buscar novas formas de engajamento político.

As características da internet, sobretudo no que diz respeito aos aspectos de interatividade e anonimidade, diferem significativamente dos meios de comunicação do passado (FRIESTAD; WRIGHT, 2005), e, como tal, provavelmente têm um efeito na socialização tradicional. Essa evolução nas tecnologias revolucionou a estrutura tradicional de relacionamento (MUSIAL; KAZIENKO, 2011), sendo a solidariedade face a face substituída por expectativas abstratas e impessoais e normas de comportamento (PHILLIPS, 2008). Para Anderson e McCabe (2012) esse fenômeno estabeleceu a internet como um mecanismo moderno de socializaçáo política da juventude, sugerindo que avanços tecnológicos de informação e comunicação podem ser poderosos indutores de atitudes e de comportamentos dos cidadáos. Segundo Area (2011, p. 22), hoje em dia "el joven [...] que no tiene un espacio propio y reconocible en internet no existe en el ciberespacio y, en consecuencia, está aislado y sin identidad en el ecosistema de comunicación digital”.

A internet, portanto, serve como agente que sedimenta as bases de um contexto interativo no qual ocorrem a socializaçâo e o desenvolvimento da identidade. A ausência dos agentes convencionais de socializaçáo adulta nesse contexto desafia a perspectiva tradicional de socialização, resultando em um processo de autossocialização (ANDERSON; MCCABE, 2012).

Nesse "novo" processo de socialização, um aspecto notável é a quantidade de tempo sem precedentes que os adolescentes passam na internet. No Brasil, segundo o Instituto Brasileiro de Geografia e Estatística - IBGE (2013), 49,4\% da população utiliza a internet, sendo maior o uso por parte dos mais jovens -: entre 15 e 17 anos, 75,7\% acessam a internet; entre 18 e 19 anos, 73,8\%; e entre 20 e 24 anos, 70,5\%.

A utilização constante da internet pelos jovens e as mobilizaçóes políticas na forma de protesto, utilizando tanto ferramentas digitais quanto demonstraçóes presenciais, parecem desmentir o estereótipo tradicional sobre a apatia e o desinteresse político dos jovens de hoje. Entretanto, tais iniciativas, em nossa opinião, da mesma forma que no passado, parecem não afetar estruturalmente o grau de engajamento político da juventude, conduzindo-os da movimentação das ruas para a política institucionalizada - eleiçóes, política partidária, plataformas e capacidade de negociar que, ao contrário, tem se mantido basicamente inerte. 
É essa postura de desmobilização e desmotivação dos jovens que geralmente se institucionaliza após surtos de participaçáo, que compromete o fortalecimento democrático em longo prazo, produzindo, ao mesmo tempo, hostilidade e conformismo político. O padrão oscilante de participação política dos jovens, que inicia com força e vigor, é, em geral, seguido de sentimentos de impotência e desilusão política.

Nesse contexto, embora o desenvolvimento das tecnologias de informação e comunicação possa ser comemorado, há que se questionar a direção de sua influência nos campos social e político. Poderia a tecnologia per se produzir mudanças sociais e políticas significativas? Qual sua influência no engajamento social e político de jovens cidadãos? Que identidade cultural a internet vem promovendo entre os jovens? Que valores sociais e políticos estão sendo construídos por eles?

Não se pode negar que a internet tem proporcionado maior transparência e aumento de visibilidade de grupos tradicionalmente marginalizados, sobretudo em comparaçáo com a mídia escrita e a televisiva. Ela tem se tornado uma mídia com rápida expansão entre os jovens, contribuindo para a construção de valores sociais e políticos.

Porém, a análise do processo de socialização política requer, além do nível individual, a consideração de contextos históricos e políticos nos quais esse se realiza, conforme assinala Owen (2008). Para Almond e Verba (1963), a socialização política não somente nos dá um insight a respeito do padrão de cultura política e subculturas em uma sociedade, mas também indica onde qualidades particulares e elementos estão sendo sustentados ou modificados. Cabe, assim, problematizar a influência do contexto na cultura política da juventude.

\section{Cultura política juvenil}

Em trabalhos recentes (BAQUERO; MORAIS, 2014), tem-se argumentado que, ao se discutir o tema da qualidade da democracia no Brasil como indutor de uma cultura política crítica, é preciso destacar que a concepção de democracia contemporânea, para além da dimensão formal, necessita incluir a dimensáo substantiva. Incluir essa dimensáo desloca a atenção para o papel do cidadão na sustentação e no fortalecimento do sistema democrático.

A introdução de estruturas democráticas por si só não conduz ao fortalecimento de uma cultura política democrática se, concomitantemente, traz consigo atributos negativos de prática política, tais como: o clientelismo, o patrimonialismo e o individualismo. São esses fatores que ainda exercem papel decisivo nas percepçóes, nas atitudes e nos comportamentos dos jovens, produzindo ou não uma cultura política participativa.

Uma cultura política democrática pressupóe a evolução simétrica entre economia e política. Quando a legitimidade da democracia é comprometida pela 
sua baixa qualidade perante situaçóes de assimetria, instala-se a desconfiança entre os jovens cidadãos. Tal desconfiança na política gera uma ambivalência atitudinal e comportamental que se manifesta nos diferentes níveis de adesão dos jovens cidadãos ao regime. Confiar ou não resulta do tipo de aprendizado que eles internalizam sobre a política e as suas instituiçóes em um determinado contexto. Dessa forma, elementos históricos e socioculturais assumem centralidade na construção de uma cultura política.

É também a qualidade da informação que afeta os tipos de valores e crenças que os jovens internalizam na conformaçáo de sua personalidade política. A informação e o conhecimento passam, assim, a se constituir em pré-requisitos na construção de uma cultura política assertiva, e não de lealdade tradicional (DALTON; WELZEL, 2014). Nesse contexto, cabe perguntar se a internet via redes sociais pode vir a ser uma ferramenta tecnológica de agregação de interesses na promoção de uma sociedade mais igualitária e inclusiva para os jovens.

A resposta a essa indagação sugere a relevância do debate sobre a inclusão social da juventude contemporânea na "sociedade virtual" com base nas redes sociais via internet. A esse respeito, Loader (1998) argumenta que a desigualdade social se reproduz no cyber espaço da mesma forma que na sociedade real. $\mathrm{O}$ autor argumenta que, para a maioria da população mundial, a possibilidade de construir identidades virtuais depende preponderantemente de sua situação material. A maioria das pessoas, segundo ele, não são livres para escolher, pelo contrário, estấo sujeitas a uma variedade de condiçóes icônicas e sociais que estruturam e articulam suas oportunidades de ação. Nessa direção, a pesquisa realizada por Putnam (2015), nos Estados Unidos, constatou que a condição socioeconômica dos jovens determina o uso que se dá a internet — para fins informativos ou de entretenimento. No caso brasileiro, tal situaçáo não é diferente, não só pelas razóes supracitadas, mas também pelos tipos de subculturas políticas juvenis que se produzem; o que pode explicar a desconexão entre práticas cívicas e o processo democrático estabelecido.

Continua a se observar que a juventude manifesta, em relação à política, atitudes e comportamentos contraditórios. Por um lado, os jovens demandam mais espaços de participação; por outro lado, são cada vez mais cínicos a respeito das instituiçóes político-democráticas representativas. Esse paradoxo é uma consequência do processo de construção democrática, no qual a institucionalização da democracia eleitoral ocorre, simultaneamente, com um crescimento do distanciamento da juventude da arena política convencional. Sob essas circunstâncias, aumenta a probabilidade de emergir uma cultura política híbrida.

Nesse sentido, os jovens manifestam, em um senso difuso, um forte apoio à democracia e, simultaneamente, há um crescimento em protestos, na desconfiança com a política e na busca por outras formas de engajamento político, que não as formas de participaçáo convencionais. Nesse contexto, as novas tecnologias de in- 
formação e comunicação, especialmente a internet, têm possibilitado a utilização de redes virtuais como instrumento de expressão da insatisfação com a situação política e econômica do país. Como essas novas ferramentas afetaráo as formas de apresentação das demandas da juventude para o Estado é incerto, uma vez que, comparativamente com dados de pesquisas realizadas no passado, os jovens continuam a apresentar semelhanças nas suas atitudes e nos seus comportamentos.

Por exemplo, em pesquisa sobre socializaçáo política conduzida pelo Núcleo de Pesquisas sobre América Latina (NUPESAL-UFRGS), em 2001, em Porto Alegre, se constatou a existência de uma reduzida mobilização política em relação à participação em movimentos tanto formais quanto não convencionais ou informais. Os dados indicaram que $78 \%$ dos jovens não se interessavam por política e $45 \%$ não estavam motivados a participar de atividades políticas com outras pessoas.

Rute Baquero (2008), em pesquisa survey sobre socialização política em Porto Alegre, em 1999 e 2002, constatou a preponderância da participação da juventude em atividades sociais, esportivas e culturais, uma reduzida participação em atividades políticas - tanto convencionais quanto não convencionais - assim como um crescente envolvimento da juventude em novos movimentos sociais e atividades comunitárias. Padrão semelhante foi observado em estudos em diferentes cidades brasileiras, conforme Cunha (2005), Silveira (2005), Araújo (2002) e Von Randow (2009).

Em pesquisas conduzidas em 2002, em diferentes cidades da Região Sul do Brasil, questóes abertas foram utilizadas com o objetivo de compreender como a juventude entendia o processo de construçáo da política. Esses estudos (LUCAS, 2003, em Caxias do Sul/RS; BAQUERO, 2004, em Porto Alegre/RS; e NAZZARI, 2003, em Cascavel/PR) mostraram resultados emblemáticos em relaçáo à forma como os jovens construíam suas representaçôes de instituiçóes políticas, geralmente de natureza negativa.

Há mudanças nesse quadro com o advento de novas tecnologias de informação e comunicação? Qual a relação entre a internet e a consolidação da democracia? Os resultados são contraditórios. No caso da China, Chen (2015) refere que a esperança de que a internet possa contribuir para um processo de democratizaçáo no regime autoritário tem sido considerada reduzida, apesar da mídia digital no país ter proporcionado a milhōes de cidadãos, no que pese as desigualdades sociais, oportunidades de participaçáo cívica. Por outro lado, em estudo empírico, Xenos e Moy (2007) identificaram uma relação positiva entre o uso da internet e a participação cívica em sociedades democráticas. Nesse sentido, parece pertinente afirmar que, nas sociedades abertas de massas de um mundo globalizado no qual se inclui o Brasil, a internet exerce uma influência poderosa nas crianças e nos jovens (VALENTINE; HOLLOWAY, 2001), afetando seu processo de socialização.

Nesse contexto, a internet vem sendo valorizada por proporcionar recursos para que jovens expressem e atualizem valores, interesses e princípios que 
moldam seu comportamento em relação à política. Isso traz à tona a discussão da relação entre o crescimento individual e um sistema democrático saudável (DEWEY, 1916). A esse respeito, o já clássico estudo de Almond e Verba (1963) sobre a construção de uma cultura política democrática mostrava que atitudes democráticas são efetivamente internalizadas pela juventude via educação em outras palavras, pelo processo de socialização política.

A mobilização via internet tem sido utilizada principalmente pelos jovens e tem se constituído em um mecanismo complementar ou como substituto da participação política convencional. Movimentos sociais catalisados pelas redes digitais são indicadores de expectativas de informação e preferências da juventude. No entanto, o que parece estar ausente são as conexôes entre a juventude que demanda relaçóes de comunicação autônomas e expressivas e as instituiçóes governamentais que determinam as políticas públicas.

Esses fatores, argumentamos, condicionam os tipos de culturas políticas juvenis que se desenham para o futuro, a despeito dos avanços nas tecnologias de informação e comunicação, conforme os dados empíricos indicam.

\section{Dimensão empírica}

Um dos principais argumentos para determinar se houve uma mudança de opinióes e comportamento político dos jovens residiria no fato de que as agências tradicionais de socializaçáo política estariam diminuindo de importância, sendo substituídas pela comunicação digital via redes sociais. Para avaliar se tal processo está ocorrendo com os jovens nas cidades pesquisadas no Sul do Brasil, examinamos, comparativamente, com quem eles costumam conversar sobre política. Se a internet está se constituindo em uma nova agência de socialização política, esperar-se-ia uma preferência maior pelos contatos nas redes sociais. No entanto, os dados apresen-

\section{Tabela 1}

Com quem você costuma conversar frequentemente sobre assuntos políticos?

\begin{tabular}{l|c|c}
\hline \multirow{2}{*}{ Instituiçóes } & \multicolumn{2}{|c}{ Frequentemente (\%) } \\
\cline { 2 - 3 } & Porto Alegre & Curitiba \\
\hline Pais & 26 & 18 \\
\hline Familiares & 10 & 7 \\
\hline Amigos & 15 & 11 \\
\hline Contatos nas redes sociais & 4 & 2 \\
\hline Colegas de escola & 15 & 10 \\
\hline Professores & 24 & 25 \\
\hline
\end{tabular}

Fonte: Nupesal (2015 e 2016).

$n$ Porto Alegre $=690 ; n$ Curitiba $=775$. 
tados na Tabela 1 indicam que as agências tradicionais de transmissão de valores políticos continuam a ter uma influência importante no comportamento de jovens nas cidades pesquisadas.

Em ordem decrescente, os jovens preferem discutir assuntos políticos com: os pais (26 e $18 \%$ — respectivamente em Porto Alegre e Curitiba), os professores (24 e $25 \%$ ), os amigos e colegas (15 e $11 \%$ ), a família (10 e 7\%) e, em último lugar, as redes sociais (4 e $2 \%$ ).

Tal padrão não se repete ao analisar as respostas dos jovens a respeito da importância de instituiçôes na formação de sua opinião sobre a arena política (Tabela 2).

Os dados da Tabela 2 indicam que a família, a internet e a escola são consideradas, em ordem decrescente, pelos jovens de Porto Alegre e Curitiba, as instituiçôes mais confiáveis na formação de sua opinião sobre política. Examinando os dados, observa-se que a internet desloca a escola, como agência tradicional de socialização política, para o terceiro lugar, constituindo-se na agência mais importante após a família e indicando seu potencial como mecanismo adicional de internalizaçâo de valores e crenças políticas por parte da juventude.

No entanto, tal constatação necessita ser relativizada ao avaliarmos os propósitos do uso da internet pelos jovens. Ao serem indagados a respeito da motivação para se conectar à internet, considerando a dicotomia entretenimento-informaçáo, os dados indicaram que 35\% dos entrevistados em Porto Alegre e 38\% em Curitiba o fazem por entretenimento e 5 e $9 \%$, respectivamente, por informação. Os demais

\section{Tabela 2}

$\mathrm{Na}$ hora de formar uma opinião sobre assuntos políticos, quais das instituiçôes abaixo você considera mais importante?

\begin{tabular}{l|c|c|c|c}
\hline \multirow{2}{*}{ Instituiçóes } & \multicolumn{2}{|c|}{ Porto Alegre } & \multicolumn{2}{c}{ Curitiba } \\
\cline { 2 - 5 } & $\begin{array}{c}\text { Em primeiro } \\
\text { lugar (\%) }\end{array}$ & $\begin{array}{c}\text { Em segundo } \\
\text { lugar (\%) }\end{array}$ & $\begin{array}{c}\text { Em primeiro } \\
\text { lugar (\%) }\end{array}$ & $\begin{array}{c}\text { Em segundo } \\
\text { lugar (\%) }\end{array}$ \\
\hline Família & 38 & 15 & 38 & 15 \\
\hline Igreja & 3 & 5 & 3 & 8 \\
\hline Escola & 18 & 16 & 19 & 17 \\
\hline Amizades & 4 & 13 & 2 & 6 \\
\hline Televisão & 7 & 10 & 13 & 17 \\
\hline Rádio & 0 & 3 & 2 & 3 \\
\hline Jornal impresso/Revista & 8 & 13 & 7 & 10 \\
\hline Internet & 22 & 25 & 16 & 24 \\
\hline Total & 100 & 100 & 100 & 100 \\
\hline
\end{tabular}

Fonte: Nupesal (2015 e 2016).

$n$ Porto Alegre $=690 ; n$ Curitiba $=775$. 
responderam que utilizam a internet com ambos os propósitos. Ao solicitar que especificassem qual era a sua principal motivação, mais de $65 \%$ informou que o estímulo central era o entretenimento. $\mathrm{O}$ que parece relevante destacar é que, embora a internet tenha se popularizado, constituindo-se em um dispositivo do dia a dia dos jovens, ela não se consolidou como mecanismo eficiente de socialização política, uma vez que a motivação principal de sua utilização é a busca pelo entretenimento.

Pensamos que fatores de contexto histórico entrelaçados com uma determinada conjuntura política do país produzem a forma como os jovens pensam a política. Nessa direçâo, realizamos um cruzamento entre as variáveis de percepção da situação do país e da forma como os jovens se sentem nesse contexto. $\mathrm{Na}$ Tabela 3, examinamos essa questấo.

A Tabela 3 indica, de forma contundente, que os sentimentos da juventude nas cidades pesquisadas são afetados pela situação dos indicadores materiais. No período da realizaçáo da pesquisa, o Brasil atravessava uma situaçáo de crise econômica e política de grandes proporçóes e com ampla divulgação pelos meios de comunicaçáo, produzindo insegurança, indignaçáo e frustraçãa nos jovens, conforme os dados da pesquisa. Os dados da Tabela 3 revelam que a maioria dos jovens experimenta um mal-estar social generalizado. A deficiência das políticas públicas no atendimento às necessidades materiais básicas afeta a forma como eles se sentem. Quando comparados os dados de sentimentos negativos com os positivos, o resultado indica que, com exceção de Porto Alegre - que nos itens moradia e transporte atingem $20 \%$ - não há sentimentos positivos por parte dos jovens.

\section{Tabela 3}

Sentimento que se tem em relação a esse momento do país.

\begin{tabular}{l|c|c|c|c|c|c}
\hline \multirow{2}{*}{$\begin{array}{l}\text { Principal } \\
\text { problema } \\
\text { do país }\end{array}$} & \multicolumn{3}{|c|}{ Porto Alegre } & \multicolumn{3}{c}{ Curitiba } \\
\cline { 2 - 8 } & $\begin{array}{c}\text { Sentimentos } \\
\text { negativos(\%) }\end{array}$ & $\begin{array}{c}\text { Sentimentos } \\
\text { positivos (\%) }\end{array}$ & $\begin{array}{c}\text { Total } \\
\mathbf{( \% )}\end{array}$ & $\begin{array}{c}\text { Sentimentos } \\
\text { negativos (\%) }\end{array}$ & $\begin{array}{c}\text { Sentimentos } \\
\text { positivos (\%) }\end{array}$ & $\begin{array}{c}\text { Total } \\
(\%)\end{array}$ \\
\hline Inflaçáa & 94 & 6 & 100 & 92 & 8 & 100 \\
\hline Desemprego & 100 & 0 & 100 & 94 & 6 & 100 \\
\hline Saúde & 96 & 4 & 100 & 100 & 0 & 100 \\
\hline Pobreza & 94 & 6 & 100 & 100 & 0 & 100 \\
\hline Corrupçáo & 96 & 4 & 100 & 98 & 2 & 100 \\
\hline Moradia & 80 & 20 & 100 & 100 & 0 & 100 \\
\hline Transporte & 80 & 20 & 100 & 0 & 0 & 0 \\
\hline Educaçáo & 99 & 1 & 100 & 98 & 2 & 100 \\
\hline
\end{tabular}

Fonte: Nupesal (2015 e 2016).

valor $p=0.05$ ( $\chi 2) ; n$ Porto Alegre $=690 ; n$ Curitiba $=775$; Sentimentos positivos (feliz, confiante, satisfeito e seguro); Sentimentos negativos (inseguro, indignado, assustado e frustrado). 
Buscando entender se as deficiências nas políticas públicas levaram esses jovens a participar das manifestações de 2013, identificamos que um percentual reduzido dos sujeitos da pesquisa marcou presença nesses episódios, tanto em Porto Alegre (20\%) quanto em Curitiba (9\%) (Tabela 4).

Indagado aos que participaram dessas manifestaçôes sobre a influência de diferentes agentes nos movimentos de rua, identificamos, em Porto Alegre, que a internet, com $55 \%$ das respostas dos jovens, foi o agente de maior influência, seguida dos amigos (45\%), dos professores $(26 \%)$, da TV (18\%) e da família $(16 \%)$. Diferentemente de Porto Alegre, os jovens de Curitiba, além da forte influência da internet (56\%), indicaram a influência destacada da família (33\%) na decisão de participar dos movimentos de rua de 2013 (Tabela 5).

Embora houvesse reduzida participação dos jovens estudantes, tanto em Porto Alegre quanto em Curitiba, nas manifestaçóes de 2013, quando indagados sobre a importância de sua participação, mais de $75 \%$ deles, em ambas as cidades, responderam que é essencial que os jovens participem da vida política (Tabela 6).

\section{Tabela 4}

Você participou das manifestaçóes de 2013?

\begin{tabular}{l|c|c}
\hline Participaçáo & Porto Alegre (\%) & Curitiba (\%) \\
\hline Sim & 20 & 9 \\
\hline Não & 80 & 91 \\
\hline Total & 100 & 100 \\
\hline
\end{tabular}

Fonte: Nupesal (2015 e 2016).

$n$ Porto Alegre $=690 ; n$ Curitiba $=775$.

\section{Tabela 5}

Influência dos meios aos jovens participantes das manifestações.

\begin{tabular}{l|c|c}
\hline Instituiçáo & Porto Alegre (\%) & Curitiba (\%) \\
\hline Família & 16 & 33 \\
\hline Igreja & 1 & 6 \\
\hline Amigos & 45 & 25 \\
\hline Professores & 26 & 31 \\
\hline TV & 18 & 23 \\
\hline Rádio & 7 & 13 \\
\hline Jornal impresso/Revista & 13 & 20 \\
\hline Internet & 55 & 56 \\
\hline
\end{tabular}

Fonte: Nupesal (2015 e 2016).

$n$ Porto Alegre $=690 ; n$ Curitiba $=775$. 
Isso sugere, em nossa opiniáo, a existência de predisposiçóes latentes à participação, por parte dos entrevistados.

Uma análise dos dados qualitativos revelou que os jovens dessas cidades justificaram a realização das manifestações devido à insatisfação com o estado das coisas - "mostrou a grande insatisfaçâo" — e à necessidade de se fazer justiça "os políticos viram que não estamos parados, queremos justiça, não confiamos neles".

Os entrevistados destacaram que os movimentos serviram para mostrar "um outro tipo de jovem" - interessado, não alienado, capaz de lutar pelos seus direitos. Nas palavras dos jovens: "mostrar que os jovens se interessam por política e não são alienados"; "mostrar que não estamos acomodados"; "mostrar que nos interessamos e nos importamos"; "mostrar que querem lutar pelos seus direitos".

No entanto, indicaram que os efeitos dessas manifestaçóes foram reduzidos e os legados na política questionáveis. Segundo os jovens: "durante algum tempo melhorou nossa sociedade"; "deu pouca diferença, certos apelos foram atendidos"; "deu uma ameaçada no Estado, mas logo passou"; "conscientizou a população e abalou os políticos"; "não que tenha tido um resultado significativo"; "não foi o suficiente para o Brasil acordar"; "mudaram algo, o mínimo".

Esses resultados nos levaram a questionar, do ponto de vista da cultura política, o grau de confiança depositada pela juventude nas instituiçóes políticas, comunitárias e sociais. Para avaliar esses dados, utilizamos a técnica de redução de dados via análise fatorial, que visa agrupar as instituições e os grupos examinados em dimensôes homogêneas. Busca-se, com essa técnica, analisar se os jovens separam suas avaliaçóes com base no tipo de instituição. Os dados são apresentados na Tabela 7.

A Tabela 7 indica que os jovens identificam com clareza as diferentes dimensões institucionais na sociedade. Tal padrão de identificação auxilia na compreensão das avaliaçóes dos jovens a respeito de grupos ou instituiçóes que são considerados parte de um mesmo conjunto. Nesse sentido, ao analisar as frequências da distribuição desses dados,constata-se que, comparativamente, entre os 7 fatores identificados, a família (89\%) é a instituição que tem maior

\section{Tabela 6}

Em sua opinião, as manifestações de 2013 foram importantes?

\begin{tabular}{l|c|c}
\hline Opiniáo & Porto Alegre (\%) & Curitiba (\%) \\
\hline Sim & 82 & 78 \\
\hline Não & 18 & 22 \\
\hline Total & 100 & 100 \\
\hline
\end{tabular}

Fonte: Nupesal (2015 e 2016).

$n$ Porto Alegre $=690 ; n$ Curitib $a=775$. 
Tabela 7

Análise fatorial de confiança nas instituições.

\begin{tabular}{|c|c|c|c|c|c|c|c|}
\hline Instituiçóes & $\begin{array}{c}\text { Confiança } \\
\text { escolar }\end{array}$ & \begin{tabular}{|c|} 
Confiança \\
nos meios de \\
comunicaçáo
\end{tabular} & \begin{tabular}{|c|} 
Confiança \\
institu- \\
cional \\
\end{tabular} & $\begin{array}{c}\text { Confiança } \\
\text { inter- } \\
\text { pessoal } \\
\end{array}$ & $\begin{array}{c}\text { Confiança } \\
\text { intra- } \\
\text { pessoal }\end{array}$ & $\begin{array}{l}\text { Confiança } \\
\text { na polícia }\end{array}$ & $\begin{array}{c}\text { Confiança } \\
\text { na igreja }\end{array}$ \\
\hline $\begin{array}{l}\text { Pessoas em } \\
\text { geral }\end{array}$ & & & & 0,71 & & & \\
\hline Pais & & & & & 0,81 & & \\
\hline Familiares & & & & & 0,68 & & \\
\hline Vizinhos & & & & 0,66 & & & \\
\hline $\begin{array}{l}\text { Colegas de } \\
\text { aula }\end{array}$ & & & & 0,58 & & & \\
\hline $\begin{array}{l}\text { Contatos das } \\
\text { redes sociais }\end{array}$ & & & & 0,70 & & & \\
\hline Amigos & & & & & 0,57 & & \\
\hline Professores & 0,44 & & & & & & \\
\hline Igreja & & & & & & & 0,75 \\
\hline $\begin{array}{l}\text { Partidos } \\
\text { políticos }\end{array}$ & & & 0,75 & & & & \\
\hline Judiciário & & & 0,50 & & & & \\
\hline Presidente & & & 0,82 & & & & \\
\hline $\begin{array}{l}\text { Governo } \\
\text { Federal }\end{array}$ & & & 0,80 & & & & \\
\hline Polícia & & & & & & 0,80 & \\
\hline $\begin{array}{l}\text { Forças } \\
\text { Armadas }\end{array}$ & & & & & & 0,85 & \\
\hline Escola & 0,62 & & & & & & \\
\hline $\begin{array}{l}\text { Movimentos } \\
\text { estudantis }\end{array}$ & 0,84 & & & & & & \\
\hline $\begin{array}{l}\text { Conselho } \\
\text { escolar }\end{array}$ & 0,82 & & & & & & \\
\hline $\begin{array}{l}\text { Grêmio } \\
\text { estudantil }\end{array}$ & 0,79 & & & & & & \\
\hline $\begin{array}{l}\text { Associaçóes } \\
\text { comunitárias }\end{array}$ & 0,71 & & & & & & \\
\hline TV & & 0,80 & & & & & \\
\hline $\begin{array}{l}\text { Jornal } \\
\text { impresso/ } \\
\text { Revista } \\
\end{array}$ & & 0,84 & & & & & \\
\hline Rádio & & 0,82 & & & & & \\
\hline Internet & & 0,56 & & & & & \\
\hline
\end{tabular}

Fonte: Nupesal (2015 e 2016).

$n$ Porto Alegre $=690 ; n$ Curitiba $=775$. 
confiança dos jovens, seguida dos amigos (65\%), da escola (49\%), da igreja (33\%), das Forças Armadas (29\%), dos meios de comunicação (26\%) e, em último lugar, das instituiçóes políticas (1\%). Esses resultados são congruentes com respostas dos jovens na pesquisa qualitativa, ao justificar a importância das manifestaçóes de 2013.

A desconfiança nas instituiçóes políticas é um traço quase universal entre os jovens. Entretanto, consideramos que, em países como o Brasil, a desconfiança nas instituições de mediação política, por parte da juventude, se constitui em constrangimento grave de constituição de uma cultura política democrática. A desconfiança nas instituiçôes responsáveis pelo bem-estar da população, no Brasil, não é um fenômeno conjuntural, e sim o resultado - conforme argumentamos no início deste trabalho - de fatores de contexto histórico e cultural que moldam a cultura política da juventude, que se orienta, preponderantemente, para uma avaliação negativa da política. Buscando dar consistência a esse argumento, utilizamos uma pergunta aberta na qual indagamos sobre qual palavra vinha na mente dos jovens quando pensavam em política, políticos, partidos políticos e cidadania. A Tabela 8 apresenta esses dados.

Tabela 8

Primeira palavra que vem à cabeça quando pensa em:.

\begin{tabular}{l|c|c|c}
\hline Temas & Tipo de sentimento & Porto Alegre (\%) & Curitiba (\%) \\
\hline \multirow{4}{*}{ Política } & Negativo & 60 & 66 \\
\cline { 2 - 4 } & Positivo & 5 & 6 \\
\cline { 2 - 4 } & Neutro & 35 & 28 \\
\cline { 2 - 4 } & Total & 100 & 100 \\
\hline \multirow{4}{*}{ Políticos } & Negativo & 89 & 88 \\
\cline { 2 - 4 } & Positivo & 1 & 1 \\
\cline { 2 - 4 } & Neutro & 10 & 100 \\
\cline { 2 - 4 } & Total & 100 & 73 \\
\hline \multirow{4}{*}{ Partidos políticos } & Negativo & 78 & 3 \\
\cline { 2 - 4 } & Positivo & 2 & 24 \\
\cline { 2 - 4 } & Neutro & 20 & 100 \\
\cline { 2 - 4 } & Total & 100 & 34 \\
\hline \multirow{3}{*}{ Cidadania } & Negativo & 35 & 11 \\
\cline { 2 - 4 } & Positivo & 8 & 55 \\
\cline { 2 - 4 } & Neutro & 57 & 100 \\
\cline { 2 - 4 } & Total & 100 & 11 \\
\hline
\end{tabular}

Fonte: Nupesal (2015 e 2016).

$n$ Porto Alegre $=690 ; n$ Curitiba $=775$. 
Da mesma forma que os resultados de pesquisas anteriores citadas neste artigo, a forma como os jovens constroem suas representaçóes a respeito da dimensão política é preponderantemente negativa. A política é percebida negativamente por $60 \%$ dos jovens em Porto Alegre e $66 \%$ em Curitiba. No caso dos políticos, essa percentagem aumenta para 89 e $88 \%$, respectivamente. Os jovens associam à política e aos políticos expressôes como "corrupção", "ladroagem" e "oportunismo". Um pouco abaixo, estão localizados os partidos políticos (78 e 73\%). Dentre as expressóes associadas pelos jovens a essa categoria estáo "alienação", "corrupção", "falsidade" e "inutilidade". No caso da percepçâo sobre a cidadania, observa-se uma alteração no padrão de respostas, deslocando-se a maior parte das opiniôes para a dimensão de neutralidade (57 e 55\%), sendo tal dimensão associada, pelos jovens, às seguintes expressóes: "conhecimento", "amizade" e "amor".

Cabe ressaltar a semelhança dos resultados nas duas cidades, apesar do trabalho de campo ter sido realizado com um intervalo de 12 meses, indicando que a internalização de valores negativos sobre a política está enraizada historicamente.

\section{Conclusões}

Este estudo mostrou que a influência de algumas agências tradicionais de socialização política, principalmente a família, continua sendo importante referência para a estruturação de valores dos jovens no Sul do Brasil. Em relação ao papel da internet como um novo agente de socialização da juventude, os dados aqui analisados revelam que os jovens estudantes indicaram sua utilização preponderantemente para entretenimento, embora também recorram a ela para obter informaçôes a respeito da política, e com base nelas estruturem atitudes e comportamentos. Dadas as características dessa mídia digital e o expertise do jovem na internet, a socialização parece ir numa direção inversa — os jovens se tornam os "adultos" nesse contexto —,resultando em uma autossocialização.

Quanto ao papel das redes virtuais, é possível observar uma dependência secundária dos jovens em relação a esse veículo de comunicação - o maior agente de influência continua sendo a família - no processo de formação de suas opinióes sobre política. Sua utilização, dessa forma, é um mecanismo de formação de identidades coletivas em um sentido mais amplo do que estritamente político.

Atividades conectadas à internet são parte importante do tempo livre dos jovens, que dedicam de cinco a seis horas diárias a essa prática. Ao participar de redes sociais via internet, a maioria dos jovens revela um senso de pertencimento, em que todos podem se comunicar e compartilhar experiências. 
No entanto, as atitudes e o comportamento dos jovens entrevistados continuam a ser impactados pela cultura política existente, e, nesse sentido, a socialização pode ser de natureza negativa, produzindo atitudes de intolerância, antagonismo, hostilidade e até agressividade. Por exemplo, os dados analisados indicam que a grande maioria dos jovens descrê da política e de suas instituiçóes, e apresenta opiniōes preponderantemente negativas em relação a essas; e, ainda, se sente indignada e frustrada com a política como um todo. Tais fatores não conduzem à institucionalização de uma cultura política juvenil assertiva e participativa, pelo contrário, reproduzem velhas práticas de relacionamento político, nas quais a internet via redes sociais se constitui em instrumento de apoio.

É muito cedo para atribuir à internet e às suas redes sociais um papel decisivo na socialização política dos jovens e na formação de outra cultura política juvenil. Há de se reconhecer, no entanto, que os movimentos patrocinados pelos jovens, nos últimos anos, têm como característica outra maneira de representar a presença coletiva no espaço público. Quiçá as açóes diretas estejam assumindo importância central, uma vez que a descrença nos canais institucionalizados de mediação política tem atingido índices alarmantes entre os jovens. A participação dos jovens na política tem em comum a mobilização individual de um sentimento de injustiça e a percepção de que foram abandonados pelo Estado. Buscam, nesse sentido, construir identificaçóes coletivas que subvertam a ordem. Nessa perspectiva, os movimentos juvenis se caracterizam por um mal-estar social com o estado das coisas, ocorrendo simultaneamente uma busca por alternativas que estimulem a participação política (FERRER, 2016).

\section{Referências}

ALMOND, G.A.; VERBA, S. The civic culture: political attitudes and democracy in five nations. Princeton: Princeton University Press, 1963.

Anderson, L.; McCabe, D.B. A coconstructedworld: adolescent self-socialization on the internet. Journal of Public Policy \& Marketing, v. 31, n. 2, p. 240-253, Fall 2012.

ARAÚJO, U. F. A construção de escolas democráticas: histórias sobre complexidade, mudanças e resistências. São Paulo: Moderna, 2002.

ARAÚJO, R. P. A.; PENTEADO, C.L.C.; SANTOS, M.B.P. Sociedade civil e políticas públicas: o uso da internet pela Rede Nossa Sáo Paulo na articulação política. In: SILVEIRA, S.A.; BRAGA; S.; PENTEADO, C. (org.). Cultura politica e ativismo nas redes digitais. São Paulo: Fundação Perseu Abramo, 2014.

AREA, M. El conocimiento en la red: la Web 2.0 en el aula. Santander: Universidad Internacional Menendez Pelayo, 2011. 
BAQUERO, M. Democracia inercial na América Latina e formas para superá-la. 2016 No prelo.

. Um caminho "alternativo" no empoderamento dos jovens: capital social e cultura política no Brasil. In: BAQUERO, M. (Org.). Democracia, juventude e capital social no Brasil. Porto Alegre: UFRGS, 2004. p. 120-146.

BAQUERO, M.; MORAIS, J. Inertial democracy, political parties and political culture in Latin America. In: CONGRESS OF POLITICAL SCIENCE, 23, 19 a 24 jul., 2014, Montreal, Canada. Anais... Montreal, Canada, 2014. v. 1. p. 1-24.

BAQUERO, R.V.A. Jovens e a participação sociopolítica: em que paradigma de participação suas açóes se inserem? In: BAQUERO, R. (Org.). Agenda jovem: o jovem na agenda.Ijuí:Unijuí, 2008. p. 123-142.

BARBER, B. Political conflict and youth. The Psychologist, v. 26, n. 5, p. 336-339, 2013.

CHEN, W (Ed.). The internet, social networks and civic engagement in Chinesesocieties.New York: Routledge, 2015.

CUNHA, P. A participação do Banco Mundial na formação cidadã dos jovens cearenses. 2005. 157f. Dissertação (Mestrado em Ciência Política) - Instituto deFilosofia e Ciências Humanas, Universidade Federal do Rio Grande do Sul, Porto Alegre, 2005.

DALTON, R.; WELZEL, C. Political Culture and Value Change. In: (Org.). The civic culture transformed. Cambridge Universit Press, 2014.

DEWEY, J. Democracy and education: an introduction to the philosophy of education. New York: Free Press, 1966 [1916].

DIAMOND, L. Political culture and democracy in developing countries. Lynne Rienner, 1994.

EGLER, T. T. C. Redes tecnossociais e democratização das políticas públicas. Sociologias, Porto Alegre, v. 12, n. 23, p. 208-236, jan./abr. 2010.

EISENBERG, J. Internet popular e democracia nas cidades. Informática Pública. Belo Horizonte, v. 1, p. 7-24, jun. 1999. Disponível em: <http://egov.ufsc.br/portal/sites/ default/files/anexos/30777-32946-1-PB.pdf>. Acesso em: 12 jul. 2016.

FEENBERG, A. Questioning technology. New York: Routledge, 1999.

FERRER, F.E. Introducción. Jóvenes movilizados en una América Latina enmovimiento. In: FERRER, F.E. (Coord.). Jóvenes en movimientos: experiencias y sentidos de las movilizaciones enla América Latina contemporánea.Buenos Aires: CLACSO, 2016.

Friestad, M.; Wright, P. The next generation: research for twenty-first-century public policy on children and advertising. Journal of Public Policy \& Marketing, v. 24, n. 2, p. 183-185, Fall 2005.

INSTITUTO BRASILEIRO DE GEOGRAFIA E ESTATÍSTICA (IBGE). Pesquisa Nacional por Amostra de Domicílios. Rio de Janeiro, 2013.

LAMB, R.; POSTER, M. Transitioning toward an internet culture: an interorganizational analysis of identity construction from online services to intranets. In: WYNN, E.; WHITLEY, E.; MYERS, M.; DEGROSS, J. (Eds.). Global and organizational discourse about information technology. Norwell, USA: Kluwer Academic Publishers, 2003. 
LOADER, B. D. A politica do ciberespaço. Lisboa: Instituto Piaget, 1997.

LUCAS, J. I. P. Juventude e antipolitica no Brasil:um estudo de cultura política e ideologia. 2003. Tese (Doutorado em Ciência Política) - Universidade Federal do Rio Grande do Sul, Porto Alegre, 2003.

MAIA, R. Democracia e a internet como esfera pública virtual: aproximação às condiçôes da deliberação. In: GOMES, W.; MAIA, R. (Orgs.). Comunicação e democracia: problemas e perspectivas. São Paulo: Paulus, 2008. p. 277-292.

MAIA, R.; CASTRO, M.C.P.S. (Org.). Midia, esfera pública e identidades coletivas. Belo Horizonte: Editora UFMG, 2006.

MERKEL, W. Defective Democracies. Instituto Juan March de Estudios e Investigaciones, Centro de Estudios Avanzados em Ciencias Sociales. Working Paper, 1999/132. Madrid, 1999.

MUSIAL, K.; KAZIENKO, P. Social networks on the Internet. World Wide Web, v. 16, n. 1, p. 31-72, 2011.

NAZZARI, R. K. Capital social, cultura e socialização política: a juventude brasileira. 2003. Tese (Doutorado em Ciência Política) - Universidade Federal do Rio Grande do Sul, Porto Alegre, 2003.

NÚCLEO DE PESQUISA SOBRE A AMÉRICA LATINA (NUPESAL) da Universidade Federal do Rio Grande do Sul (UFRGS). Banco de dados, 2001.

OWEN, D. Political Socialization in the Twenty-first Century: Recommendations for Researchers. In: CENTERFOR CIVICEDUCATIONANDTHEBUNDESZENTRALE FUR POLITISCHE BILDUNG. Conference The Future of Civic Education in the 21st Century. James Madison's Montpelier, Sept. 21-26, 2008.

PHILLIPS, D. Social inclusion, social exclusion and social cohesion: tensions in a postindustrial world. The Hong Kong Journal of Social Work, v. 42 (1/2), 2008.

PUTNAM, R. D. Our kids. The American dream in crisis. New York: Simon \& Schuster, 2015.

SILVEIRA, A. F. Capital social e educação: perspectivas sobre empoderamento da juventude de Porto Alegre. 2005. 114f. Dissertação (Mestrado em Ciência Política) Instituto de Filosofia e Ciências Humanas, Universidade Federal do Rio Grande do Sul, Porto Alegre, 2005.

SOON, C.; KLUVER, R. Uniting political bloggers in diversity: collective identity and web activism. Journal of Computer-Mediated Communication, v. 19, n. 3, p. 500-515, Apr. 2014. Disponível em: <http://onlinelibrary.wiley.com/doi/10.1111/jcc4.12079/ pdf>. Acesso em: 20 fev. 2015. DOI:10.1111/jcc4.12079.

VALENTINE, G.; HOLLOWAY, S. Parents' and children's fears about information and communication technologies and the transformation of culture and society. In: Children Tecnhology and Culture. The Impacts of Technologies in Children's Everyday Lives. New York: Routledge Falmer, 2001. p. 59-77. 
VON RANDOW, R. Juventude, participação e cultura política: um debate sobre qual (re)construção democrática? In: COLÓQUIO INTERNACIONAL DE PSICOSSOCIOLOGIA E SOCIOLOGIA CLÍNICA, 13, 2009, Belo Horizonte. Anais... Belo Horizonte, UFMG, 2009. v. 1. p. 235-235.

WEFFORT, F. C. New democracy and economic crisis in Latin America. In: OXHOM, P.; DUCATENZELLER, G. (Org.). What kind of democracy? What kind of market? Pennsylvania: University Park, 1998.

XENOS, M.; MOY, P. Direct and differential effects of the internet on political and civic engagement. Journal of Communication, v. 57, n. 4, p. 704-718, Dec. 2007.

Recebido em 30 de junho de 2016.

Aprovado em14 de outubro de 2016. 